\title{
Diffuse myocardial fibrosis, but not focal fibrosis identified with delayed enhancement, is an independent predictor of $L V$ reversed remodeling in patients with idiopathic non-ischemic cardiomyopathy
}

\author{
Teerapat Yingchoncharoen*, Scott D Flamm, Deborah Kwon \\ From 16th Annual SCMR Scientific Sessions \\ San Francisco, CA, USA. 31 January - 3 February 2013
}

\section{Background}

Diffuse myocardial fibrosis may be a fundamental features of adverse myocardial remodeling in idiopathic non-ischemiccardiomyopathy. As T1-weighted cardiac magnetic resonance (CMR) imaging provides an alternative method of diffuse fibrosis quantification, we sought to assess the association of myocardial $\mathrm{T} 1$ value to left ventricular reverse remodeling (LVRR).

\section{Methods}

We performed CMR in 24 patients with idiopathic nonischemic cardiomyopathy (16 men, mean age $58 \pm 11$ years) and also in 12 healthy volunteers as control subjects. T1 mapping was performed with post-contrast Look-Locker gradient echo. Baseline echocardiography as well as hemodynamic and metabolic data were collected at the time of CMR. Patients were followed over a median time of 8 months for LVRR which was defined as a left ventricular ejection fraction (LVEF) increase of $\geq 10 \mathrm{U}$ and a decrease in indexed left ventricular end-diastolic diameter (LVEDD) of $\geq 10 \%$ or indexed LVEDD of $<33 \mathrm{~mm} / \mathrm{m}^{2}$ at 24 months. A multivariable logistic regression analysis was performed to identify associations with LVRR.

\section{Results}

LVRR was found in 8 patients (33\%). Mean T1 value was substantially lower in patients without LVRR $(240+26)$ compared to patients with LVRR $(285+35, \mathrm{p}=0.002)$ and healthy controls $(413+57, \mathrm{p}<0.001)$ (Figure1). There was

Cleveland Clinic Foundation, Cleveland, OH, USA no significant difference in $\mathrm{T} 1$ value of the non delayedenhanced myocardium in patients with myocardial scar on delayed-enhancement imaging $(264+26)$ and without scar $(263+42, \mathrm{p}=0.233)$. LVRR was associated with baseline T1 value (HR 1.1 [95\% CI 1.01-1.19]), independent of LVEF and the presence of myocardial scar on delayed-enhancement imaging (Table 1).

\section{Conclusions}

Post contrast T1 value is a predictor of LV reversed remodeling in patients with idiopathic non-ischemic cardiomyopathy, independent of baseline LVEF and the presence of myocardial scar.

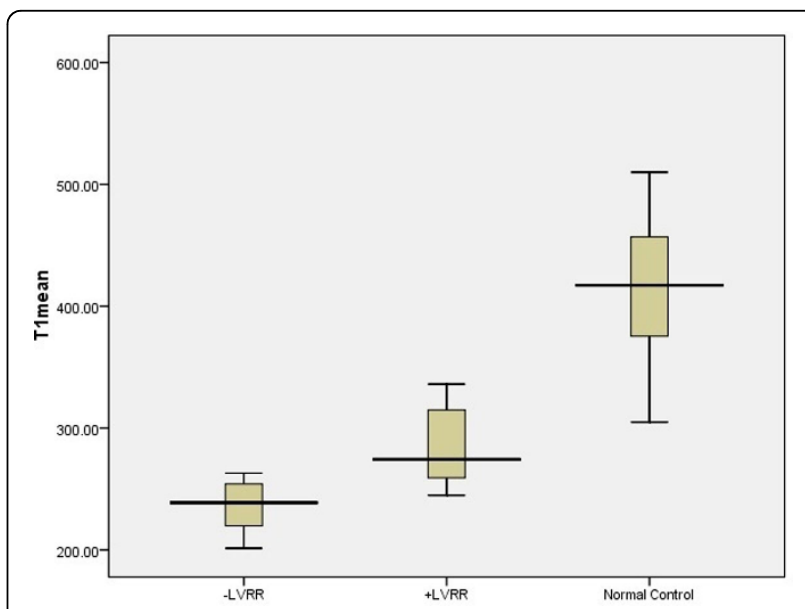

Figure 1 Comparison of myocardial T1 time between patients without LVRR, patients with LVRR and controls. 
Table 1 Multivariate analysis of baseline correlates of LVRR

\begin{tabular}{ccc}
\hline Variables & HR $(95 \% \mathrm{Cl})$ & P value \\
\hline Baseline LVEF & $0.804(0.643-1.004)$ & 0.054 \\
Presence of myocardial scar & $1.552(0.091-26.57)$ & 0.762 \\
Myocardial T1 time & $1.098(1.012-1.192)$ & 0.025 \\
\hline
\end{tabular}

\section{Funding}

None.

Published: 30 January 2013

doi:10.1186/1532-429X-15-S1-P109

Cite this article as: Yingchoncharoen et al:: Diffuse myocardial fibrosis,

but not focal fibrosis identified with delayed enhancement, is an

independent predictor of LV reversed remodeling in patients with

idiopathic non-ischemic cardiomyopathy. Journal of Cardiovascular

Magnetic Resonance 2013 15(Suppl 1):P109.

Submit your next manuscript to BioMed Central and take full advantage of:

- Convenient online submission

- Thorough peer review

- No space constraints or color figure charges

- Immediate publication on acceptance

- Inclusion in PubMed, CAS, Scopus and Google Scholar

- Research which is freely available for redistribution

Submit your manuscript at www.biomedcentral.com/submit
C Biomed Central 